\title{
The nutritional impacts of soil-transmitted helminths infections among Orang Asli schoolchildren in rural Malaysia
}

\author{
Abdulhamid Ahmed ${ }^{1 *}$, Hesham M Al-Mekhlafi ${ }^{1} 2^{*}$, Abdulelah H Al-Adhroey ${ }^{1}$, Init Ithoi ${ }^{1}$, Awatif M Abdulsalam ${ }^{1}$
} and Johari Surin ${ }^{1}$

\begin{abstract}
Background: Soil-transmitted helminths (STH) infections, anaemia and malnutrition are major public health problems in school-age children in developing countries. This study was conducted on 289 Orang Asli (aboriginal) schoolchildren in order to assess the current prevalence and predictors of anaemia and malnutrition, as well as the nutritional impacts of STH infections among these children.

Methods: A cross-sectional study was combined with a longitudinal follow-up three months after treatment with anthelminthic drugs. Blood samples were collected from the children to measure haemoglobin ( $\mathrm{Hb})$ level.

Anthropometric and socioeconomic data were also collected and the children were screened for STH.

Results: The baseline findings revealed that the prevalence of anaemia, significant stunting, underweight and wasting among the children were $41.0 \%, 28.0 \%, 29.2 \%$ and $12.5 \%$, respectively. Overall, the prevalence of trichuriasis, ascariasis and hookworm infections were $84.6 \%, 47.6 \%$ and 3.9\%, respectively. Haemoglobin level was significantly lower among the moderate-to-heavy infected children compared to the negative-to-light infected children. Age <10years and moderate-to-heavy ascariasis were the predictors of anaemia. Stunting was associated with gender, age, moderate-to-heavy ascariasis and trichuriasis. Three months post-treatment assessment showed that the moderate-to-heavy infected children gained significant increment in their mean $\mathrm{Hb}$ level compared to the negative-to-light infected children $(0.44 \mathrm{~g} / \mathrm{dL}$ compared to $0.08 \mathrm{~g} / \mathrm{dL})$. However, no difference was found in the mean increments in growth indices between the groups.

Conclusion: STH infections, anaemia and malnutrition are still prevalent and a matter of public health concern in Orang Asli communities in Malaysia. Sustainable deworming programme at school and community levels among these populations will help to improve their health and nutritional status.
\end{abstract}

Keywords: Soil-transmitted helminths, Anaemia, Malnutrition, Orang Asli, Malaysia

\section{Background}

Human beings dwelling in poor and disadvantaged communities with inadequate hygiene in the developing countries of the world continue to harbour and endure the burden of soil-transmitted helminths (STH) infections. The disease burden is mainly manifested as nutritional stress and associated with poor appetite, food indigestion and malabsorption, impaired growth and anaemia [1-3].

\footnotetext{
*Correspondence: hamidmck@yahoo.com; halmekhlafi@yahoo.com

'Department of Parasitology, Faculty of Medicine, University of Malaya, Kuala Lumpur 50603, Malaysia

Full list of author information is available at the end of the article
}

Anaemia, malnutrition and STH infections are prevalent throughout the developing nations of the world. They often occur synergistically in areas of low socioeconomic status, where they constitute a major public health problem especially among children of school age [4]. The highest prevalence of malnutrition in the world occurs in Asia where about $70 \%$ of all the children are malnourished [5].

An estimated 30\% of the world's total population are anaemic [6]. In East Asia, nearly 50\% of all the school age children are anaemic [7]. The burden of STH infections is associated with anaemia and micronutrient deficiencies such as iron, vitamins and folate. This leads to reduced 
work capacity [8], poor cognitive function [9] and pregnancy disorders [10]. Anaemia and malnutrition increase the risk and severity of infections among the affected individuals and hence, are major causes of death especially among children and pregnant women $[7,11]$. The synergistic occurrence of helminthiasis, anaemia and malnutrition exert a negative effect on growth and development of the affected person [12].

In Malaysia, STH infections, anaemia and malnutrition are still prevalent and of public health concern especially among the low income groups living in rural areas. For instance, according to the Malaysian Ministry of Health [13], $18.3 \%$ and $20.8 \%$ of pre-school girls and boys in the country were anaemic. Previous research studies among the low income groups reported prevalence rates of anaemia ranging from $24.4 \%$ - $48.5 \%$ [14-17], as well as varying degrees of malnutrition. The Orang Asli (aboriginal) population of Malaysia are known to be lagging behind in terms of educational attainment, health care and general socioeconomic status. They are also known to harbour a range of parasitic diseases including STH infections [18-20]. Hence, this study was carried out to determine the current prevalence of anaemia and malnutrition and to assess the effects of STH infections on the nutritional status of Orang Asli schoolchildren in an aboriginal setting in rural Malaysia.

\section{Methods}

\section{Study area and subjects}

The study was conducted in Satak area, Raub district, Pahang state, located about 200 kilometres northeast of Kuala Lumpur, between latitude $3^{\circ} 59^{\prime} 22^{\prime \prime} \mathrm{N}-4^{\circ} 02^{\prime} 03^{\prime \prime} \mathrm{N}$ and longitude $101^{\circ} 37^{\prime} 48^{\prime \prime} \mathrm{E}-101^{\circ} 43^{\prime} 47^{\prime \prime} \mathrm{E}$. The area comprise of five indigenous communities namely; Pos Satak, Sungai Kelang, Sungai Rensong, Ruai Hulu and Ruai Hilir. These communities are the catchment centres for the Sekolah Kebangsaan Satak (National school of Satak).

The study subjects include all the volunteered, apparently healthy children enrolled in the school at the time of the study. The school has a total enrolment of 364 pupils. However, two hundred and eighty nine (289) eligible pupils aged $6-13$ years were available during our visits to the school and they voluntarily participated in this research. Among them, 254 children delivered stool samples for examination. Despite the high response rate (88\% response rate), few aspects should be considered when conducting research among Orang Asli schoolchildren. First, risk of selection bias is present if children in high numbers are absent as the cause of the absenteeism can be related to the health problem under investigation by the research. Second, the high absenteeism rate reported among these children may result in high dropout rate and subsequently affect the power of longitudinal studies. During our visits for post-treatment assessment, few students were absent.
However, we managed to collect their blood and stool samples, and anthropometric measurements in their home settings.

\section{Study design}

This was a cross-sectional study with a longitudinal followup (pre and post-treatment assessment). Anthropometric data, stool and blood samples were collected from the subjects at baseline (pre-treatment) and at follow-up (three months post-treatment). Due to ethical reasons we could not use a placebo control group. However, data were compared between the children who had moderate-to-heavy infections with STH and those who were un-infected or had only light infections (negative-to-light). It is well documented that moderate-to-heavy STH infections are clinically significant and are associated with a wide range of symptoms, whereas light infections are usually asymptomatic. Moreover, stunting which represents a state of chronic nutritional stress is often seen as the best indicator of malnutrition [21]. Hence, in this study, nutritional differences between the groups of the children were calculated with reference to the prevalence of significant stunting.

\section{Questionnaire}

Socioeconomic and demographic data of the participants were collected using a pre-tested questionnaire. Several visits were paid to the villages, where the children and their parents were interviewed in order to gather information on their socioeconomic status, personal hygiene practices and medical history.

\section{Haemoglobin assessment}

Haemoglobin $(\mathrm{Hb})$ level of each child was measured on the spot by trained nurses. A finger pricks blood was obtained from each child and assessed directly by using the Hemocue hemoglobinometer (Hemo Cue, AB, Angelhom, Sweden). All children with $\mathrm{Hb}$ level $<12 \mathrm{~g} / \mathrm{dL}$ were considered to be anaemic [6].

\section{Anthropometric assessment}

Height and weight of all the subjects were measured and recorded separately by two researchers to avoid intrahuman errors, and the average measurements for each child were used for the data analysis. The children were measured wearing light uniforms, without shoes, belts, caps or any other material that could tamper with their actual heights and weights. Weight was measured to the nearest $0.1 \mathrm{~kg}$ using a SECA Scale. Height was recorded to the nearest $0.1 \mathrm{~cm}$, using the same device which has a vertical scale and a head piece attached to it for height measurement. 


\section{Parasitology}

Fresh stool samples were collected from 254 subjects in clearly labelled containers with wide mouth and screw cap. Appropriate demonstrations on how to collect the stool samples were conducted to them to avoid possible contamination in the process of collection at home. The collected stool samples were transported immediately in suitable ice boxes for analysis at the stool processing laboratory of the department of Parasitology, University of Malaya. The samples were analyzed using the Kato-Katz and Harada Mori Techniques [22]. Egg counts were read accordingly and recorded as eggs per gram of faeces (epg). Intensity of infection was determined and recorded as light, moderate or heavy according to the WHO guidelines [23]. Duplicate Kato-Katz slides were prepared from each stool specimen and all were examined twice by two different microscopists and the average readings were used to make this report.

\section{Anthelminthic treatment}

All the infected children were treated with a 3-day course of $400 \mathrm{mg}$ albendazole tablets, Zentel ${ }^{\circledR}$ (GlaxoSmithKline, London, UK). The drugs were administered by a team of medical personnel, the researchers and the school's deputy headmaster in a direct observed therapy. The orange flavour of the drugs encouraged the children to chew the tablets before swallowing. Packets of fruit juices were also given to them to drink along with the tablets. About 14 days after deworming, stool samples were collected again from the pupils and examined in order to ascertain the efficacy of the drug. Light infections were still detected in 20 (8.4\%) children (16 with trichuriasis and 4 with ascariasis), and were treated accordingly with a single dose of $400 \mathrm{mg}$ albendazole to ensure complete deworming.

\section{Statistical analysis}

The anthropometric data of the children was analyzed by using the Epi-Nut component of the EpiInfo software (version 3.4.3, 2007, Centre for Disease Control and Prevention, Atlanta, Georgia, USA), to obtain the relevant Z-Scores for Height-for-Age (HAZ), Weight-for-Age (WAZ) and Weightfor-Height (WHZ). The values were assessed with reference to the National Centre for Health Statistics (NCHS) and the WHO values. Children who had Z-Scores $<-2$ SD of the NCHS reference values were considered as significantly malnourished. Data analysis was performed by using the SPSS software version 13.0 for windows (SPSS, Chicago, IL. USA). The distribution of quantitative data was examined using the Shapiro-Wilk test and found to be normal. The level of significance of 0.05 was used for all the statistical tests. Univariate analysis was used to assess the risk factors of anaemia and significant stunting among the subjects. However, variables that showed association with a $P$-value $\leq 0.20$ were used to develop a stepwise forward multiple regression model, in order to retain all possible significant associations of related variables with anaemia and stunting [24]. Independent t-test was used to examine the differences and improvements in $\mathrm{Hb}$, weight and height between groups. Repeated measures analysis of variance (ANOVA) was used to compare the $\mathrm{Hb}$, weight and height at pre-treatment and post-treatment assessments, after adjusting for the age and sex of the participants. Moreover, analysis of covariance (ANCOVA) was used to adjust for the effect of the pre-treatment $\mathrm{Hb}$ level as a covariate.

\section{Ethical consideration}

The protocol of this study was reviewed and approved by the Medical Ethics Committee of the University of Malaya Medical Centre, Kuala Lumpur (Reference Number: 788.74). Oral informed consent was duly obtained from all the study subjects, their parents and the school authority before embarking on the survey. Written permission was also obtained from the education authorities in Raub district. The objectives and protocols of the research were thoroughly discussed with the community leaders and school management for proper clarification. It was agreed that, participation in the research is voluntary and that subjects may withdraw from the research at any time without prior notice.

\section{Results}

A total of two hundred and eighty nine pupils (140 males and 149 females), aged $6-13$ years old with a mean age of $9.7 \pm 0.2$ years participated in this study. About half of the parents had no formal education and almost two thirds of the children belong to families with low monthly income (<RM500.00/month; 1US\$ = RM3.00). Almost half (53\%) of the children were $\geq 10$ years old and about one fifth of all the children belong to large family settings ( $>7$ members). About half of the households in the study area have no toilet facilities, rivers were used as the preferred defaecation sites as well sources of water for domestic usage. Only about one fifth of the households in the area have access to piped water supply. The results of this study showed that $93.7 \%$ of all the participants were infected with at least one species of STH.

The prevalence of trichuriasis, ascariasis and hookworm infections were $84.6 \%, 47.6 \%$ and $3.9 \%$, respectively. Among those, about a quarter of the infections by Ascaris lumbricoides and nearly half of those by Trichuris trichiura were of moderate-to-heavy intensities, whereas, all hookworm infections were of light intensity. Overall, the combined moderate-to-heavy STH infections accounted for $60.5 \%$ of all the infections. Data on the STH prevalence and distribution among these children have been published previously [18]. 
At baseline, the mean haemoglobin levels of the participants was $12.2 \pm 0.14 \mathrm{~g} / \mathrm{dL}$, and $96(41.0 \%)$ of the subjects were found to be anaemic. Moreover, the mean weights and heights of the study subjects were $24.2 \pm 0.44 \mathrm{~kg}$ and $126.8 \pm 0.61 \mathrm{~cm}$, respectively. The prevalence of significant stunting, underweight and wasting was $28.0 \%, 29.2 \%$ and $12.5 \%$, respectively. The baseline anthropometric characteristics of the moderate-to-heavy STH infected and the negative-to-light infected children showed that there is no significant difference $(P>0.05)$ in terms of weight and height among them. However, the children who had moderate-to-heavy STH infections had significantly lower mean haemoglobin concentration compared to those who had negative-to-light infections $(11.9 \mathrm{~g} / \mathrm{dL}$ compared to $12.6 \mathrm{~g} / \mathrm{dL} ; P=0.005)$. Although the children who had moderate-to-heavy infections were more anaemic compared to the negative-to-light infected group, the difference was not statistically significant $(P=0.099)$. The general baseline anthropometric and nutritional characteristics of the two groups of subjects are shown in Table 1.

Examining the association of anaemia with the possible risk factors revealed that age $<10$ years $\left(x^{2}=4.817\right.$; $P=0.028)$ and moderate-to-heavy ascariasis $\left(x^{2}=3.867\right.$; $P=0.049)$ were significantly associated with anaemia (Table 2). Multivariate analysis using logistic regression confirmed that age $<10$ years $(\mathrm{OR}=2.11 ; 95 \% \mathrm{CI}=1.23$, 3.63; $P=0.007)$ and moderate-to-heavy ascariasis $(\mathrm{OR}=$ $2.05 ; 95 \% \mathrm{CI}=1.12,3.76 ; P=0.021)$ as the main predictors of anaemia among the study subjects (Table 3 ).

The association of stunting with socioeconomic and health factors among the children that participated in this study was examined and the result showed that, gender (male) $\left(\chi^{2}=4.137 ; P=0.042\right)$, age $\geq 10$ years $\left(\chi^{2}=32.86 ; P<0.001\right)$, moderate-to-heavy ascariasis $\left(\chi^{2}=5.687 ; P=0.017\right)$ and moderate-heavy trichuriasis $\left(\chi^{2}=5.069 ; P=0.024\right)$ were significantly associated with stunting (Table 4). Logistic regression analysis confirmed age $\geq 10$ years $(\mathrm{OR}=5.06$; 95\% $\mathrm{CI}=2.60,9.87 ; P<0.001)$, male gender $(\mathrm{OR}=2.82$; $95 \% \mathrm{CI}=1.48, \quad 5.39 ; \quad P=0.002)$ and moderate-to-heavy ascariasis $(\mathrm{OR}=2.17 ; 95 \% \mathrm{CI}=1.10,4.26 ; P=0.025)$ as the main predictors of stunting among these children (Table 5).

Three months after the administration of anthelminthic treatment to all the infected children, the mean increments in $\mathrm{Hb}$ and anthropometric indices between the negative-tolight and the moderate-to-heavy infected groups were assessed (Table 1). The result showed that the mean increments in $\mathrm{Hb}$ levels was significantly higher among moderate-to-heavy infected group as compared to the negative-to-light infected group $(0.44 \mathrm{~g} / \mathrm{dL}$ compared to 0.09 $\mathrm{g} / \mathrm{dL} ; t=-1.987 ; P=0.048)$. The repeated measures ANOVA showed that the $\mathrm{Hb}$ level increased significantly $(\mathrm{F}=9.243$; $P=0.003$ ) among the moderate-to-heavy STH group $(12.4 \mathrm{~g} / \mathrm{dL}$ vs $11.9 \mathrm{~g} / \mathrm{dL})$ as compared to the negative-to-light infected group (12.5 g/dL vs $12.6 \mathrm{~g} / \mathrm{dL}$ ) (Figure 1). After adjusting for the effects of age and gender of participants (using repeated measures ANOVA), and the pre-treatment $\mathrm{Hb}$ level (using ANCOVA), the difference in $\mathrm{Hb}$ increments between the two groups remained significant. On the other hand, the results of repeated measures ANOVA showed no significant difference in the mean increments of weight and height between the two groups $(P>0.05)$.

\section{Discussion}

To the best of our knowledge, this is the first crosssectional study with a longitudinal follow-up that attempts

Table 1 Nutritional characteristics of the participants according to STH infections $(\mathbf{n}=\mathbf{2 5 4})$

\begin{tabular}{|c|c|c|c|c|}
\hline \multirow[t]{2}{*}{ Variables } & \multirow[t]{2}{*}{ All subjects $(n=254)$} & \multicolumn{3}{|c|}{ STH infections } \\
\hline & & Negative-to-light $(n=110)$ & Moderate-to-heavy $(n=144)$ & $P$ \\
\hline \multicolumn{5}{|c|}{ Before treatment (Baseline) } \\
\hline Haemoglobin $(\mathrm{g} / \mathrm{dL})^{*}$ & $12.2 \pm 0.14$ & $12.6 \pm 0.14$ & $11.9 \pm 0.13$ & $0.005 t$ \\
\hline Weight $(\mathrm{kg})^{*}$ & $24.2 \pm 0.44$ & $23.9 \pm 0.42$ & $24.4 \pm 0.54$ & 0.607 \\
\hline Height $(\mathrm{cm})^{*}$ & $126.8 \pm 0.61$ & $125.9 \pm 0.95$ & $127.5 \pm 0.75$ & 0.198 \\
\hline Anaemiat & $96(40.2)$ & $34(34.0)$ & $62(44.6)$ & 0.099 \\
\hline Significant stuntingt & $63(24.8)$ & $18(16.4)$ & $45(31.3)$ & $0.006 t$ \\
\hline Significant underweight† & $68(26.9)$ & $30(27.3)$ & $38(26.6)$ & 0.901 \\
\hline Significant wasting $†$ & $35(13.8)$ & $20(18.2)$ & $15(10.4)$ & 0.075 \\
\hline \multicolumn{5}{|c|}{ Improvements after treatment } \\
\hline Haemoglobin $(\mathrm{g} / \mathrm{dL})^{*}$ & $0.29 \pm 0.07$ & $0.09 \pm 0.04$ & $0.44 \pm 0.12$ & $0.048 \%$ \\
\hline Weight $(\mathrm{kg})^{*}$ & $1.16 \pm 0.06$ & $1.10 \pm 0.07$ & $1.20 \pm 0.08$ & 0.459 \\
\hline Height $(\mathrm{cm})^{*}$ & $1.22 \pm 0.07$ & $1.30 \pm 0.09$ & $1.15 \pm 0.09$ & 0.288 \\
\hline
\end{tabular}

*Values are mean \pm SEM; Independent samples t-test.

†Values are number (\%); Chi square test.

†Significant difference between groups. 
Table 2 Univariate analysis for the potential risk factors of anaemia among Orang Asli schoolchildren in Satak, Pahang $(\mathbf{n}=\mathbf{2 5 4})$

\begin{tabular}{lll}
\hline Variables & $P$ \\
\cline { 2 - 3 } & Prevalence (\%) & OR $(95 \% \mathrm{Cl})$ \\
\hline
\end{tabular}

\section{Gender}

Male

Female

\section{Age group}

$<10$ years

$\geq 10$ years

Mother's educational level

No formal education

$\geq 6$ years formal education

Mother's employment status

Not working

Working

Family Size

$>7$ members

$\leq 7$ members

\section{Household monthly income}

$<$ RM500.00

$\geq$ RM500.00

\section{Ascaris infection}

Moderate-to-heavy

Negative-to-light

Trichuris infection

Moderate-to-heavy

Negative-to-light

Hookworm infection

Positive

Negative

Stunting

Significant

Normal/mild

Underweight

Significant

Normal/mild

\section{Wasting}

Significant

Normal/mild

*Significant association $(P<0.05)$.

to investigate the impact of STH infections on the nutritional status of Orang Asli children in Malaysia as well as the possible benefit of deworming on the affected individuals. STH infections, anaemia and malnutrition remain among the major public health problems afflicting
Table 3 Multivariate analysis for the potential risk factors of anaemia among Orang Asli schoolchildren in Satak, Pahang $(\mathbf{n}=\mathbf{2 5 4})$

\begin{tabular}{|c|c|c|}
\hline \multirow[t]{2}{*}{ Variables } & Anaemia & \multirow[t]{2}{*}{$P$} \\
\hline & OR $(95 \% \mathrm{Cl})$ & \\
\hline Age ( $<10$ years $)$ & $2.11(1.23,3.63)$ & $0.007^{*}$ \\
\hline Gender (male) & $1.49(0.87,2.57)$ & 0.149 \\
\hline Ascaris infections (Moderate-to-heavy) & $2.05(1.12,3.76)$ & $0.021^{*}$ \\
\hline $\begin{array}{l}\text { Mother's educational level } \\
\text { (No formal education) }\end{array}$ & $1.37(0.78,2.41)$ & 0.270 \\
\hline Household monthly income (<RM500) & $1.35(0.75,2.42)$ & 0.312 \\
\hline
\end{tabular}

underprivileged people, particularly in developing countries [4]. Children from rural communities tend to be more vulnerable due to their low socioeconomic status and social isolation [25]. It is estimated that Asia had the highest number of malnourished children in the world [5].

The findings of our study indicated that $41.0 \%$ of all the subjects examined were anaemic. This is in agreement with the results obtained in previous studies among aboriginal children in Malaysia [14,15]. A similar prevalence was reported elsewhere [26,27]. However, lower prevalence rate was reported among the Malaysian adults [17]. The high prevalence reported in this study could be related to the fact that the study population live in remote rural communities with high rate of poverty which contribute to poor access to good diet and proper healthcare.

The results of this study also showed that malnutrition is common among the study subjects. The prevalence of significant stunting, underweight and wasting were; $28.0 \%$, $29.2 \%$ and $12.5 \%$, respectively. Our findings were consistent with the results of some previous reports among some Malaysian populations [19,28,29]. Higher prevalence of malnutrition was also reported in India [30], Nigeria [31], and Brazil [32]. The high prevalence of malnutrition by our study likely reflects the low socioeconomic status of most of the households in Orang Asli communities. Low socioeconomic status relates to poverty which affects the purchasing power of an individual or group, hence affecting the dietary intake. The long established synergism with helminthiasis may also contribute to the high prevalence of malnutrition among these subjects.

Our study showed that age $<10$ years was a significant risk factor of anaemia among these children. This is consistent with the findings by Calis et al., [33] who reported that the Malawian pre-school and early school-age children had the highest risk of anaemia. It is also in agreement with the findings of a previous study among Orang Asli children by Al-Mekhlafi et al., [14] which demonstrated that the prevalence of anaemia decreased significantly with age. It 
Table 4 Univariate analysis for the potential risk factors of stunting among Orang Asli schoolchildren in Satak, Pahang $(n=254)$

\begin{tabular}{lll}
\hline Variables & Significant stunting & $P$ \\
\cline { 2 - 2 } & Prevalence (\%) OR (95\% Cl) \\
\hline
\end{tabular}

\section{Gender}

Male

Female

Age group

$\geq 10$ years

$<10$ years

Mother's educational level

No formal education

$\geq 6$ years formal education

Mother's employment status

$\begin{array}{lll}\text { Not working } & 28.5 & 1.59(0.45,5.38) \\ \text { Working } & 2.477\end{array}$

Family size

$>7$ members

$\leq 7$ members

Household monthly income

$<$ RM500

$\geq$ RM500

Ascaris infection

Moderate-to-heavy

Negative-to-light

Trichuris infection

\begin{tabular}{llll} 
Moderate-to-heavy & 31.0 & $1.94(1.09,3.48)$ & $0.024^{*}$ \\
Negative-to-light & 18.8 & 1 \\
Hookworm infection & & \\
$\quad$ Positive & 10.0 & $0.33(0.04,2.63) 0.269$ \\
Negative & 25.4 & 1 \\
Anaemia & & \\
Anaemic & 26.8 & $0.95(0.77,1.18)$ & 0.664 \\
Normal & 29.2 & 1 & \\
\hline
\end{tabular}

*Significant association $(P<0.05)$.

is well known that females tend to be more anaemic than males especially in the reproductive age as a result of physiological differences. However in the present study no significant difference in the prevalence of anaemia was found between males and females. Previous studies from Kenya [34] and Tanzania [35] demonstrated high prevalence of anaemia among the male compared to the female schoolchildren.

Moderate-to-heavy ascariasis was also found to be significantly associated with anaemia among these subjects. The association between anaemia and intestinal helminthiasis has been reported previously [15,31]. However, in a
Table 5 Multivariate analysis for the potential risk factors of stunting among Orang Asli schoolchildren in Satak, Pahang $(n=254)$

\begin{tabular}{|c|c|c|}
\hline \multirow[t]{2}{*}{ Variable } & Significant stunting & $P$ \\
\hline & \multicolumn{2}{|l|}{ OR $(95 \% \mathrm{Cl})$} \\
\hline Age ( $>10$ years) & $5.06(2.60,9.87)$ & $<0.001^{*}$ \\
\hline Gender (Male) & $2.82(1.48,5.39)$ & $0.002^{*}$ \\
\hline Ascaris infections (Moderate-to-heavy) & $2.17(1.10,4.26)$ & $0.025^{*}$ \\
\hline Trichuris infections (Moderate-to-heavy) & $1.36(0.71,2.60)$ & 0.358 \\
\hline
\end{tabular}

OR: odds ratio; $\mathrm{Cl}$; Confidence interval.

*Significant risk factor $(P<0.05)$.

Variables entered in the model were age, gender, moderate-to-heavy ascariasis and moderate-to-heavy trichuriasis.

previous study among Malaysian adults [17], no association was found between anaemia and helminth infections, probably due to the very low prevalence of helminth infections. It was suggested that blood loss due to hookworm and $T$. trichiura infections strongly correlated with worm load [36]. Moreover, it was reported that even light hookworm infections could be associated with lower haemoglobin concentration and higher prevalence of anaemia [34]. Although ascariasis is known to influence the nutritional status, its impact on anaemia is less clear [37]. The strong association between anaemia and moderate-to-heavy ascariasis observed among these children could be attributed to the heavy intensity of infections and the long synergism with other contributory factors such as poverty and poor dietary intake. As a limitation, the present study did not measure the daily iron intake. However, a previous study had shown that the daily iron intake by Orang Asli children in rural Malaysia was only about $29 \%$ to $49 \%$ of the recommended daily intake [14].

Our investigation revealed that children below the ages of 10 years old were significantly less stunted compared to those $\geq 10$ years. This is in agreement with previous similar studies [38-40]. It has been established that stunted children continue to deviate from normal growth with increasing age. Hence, the risk of becoming stunted continues as children get older. In this study, male children tend to be significantly more stunted than the females. Male sex, have been reported as a risk factor of stunting in a previous study in Indonesia [40]. Conversely, in a study among under-five children in Nepal, girls were reported to be at higher odds for stunting [41]. We assume that the higher odds of stunting among the boys in our study could be attributed to limited food supply in many households and coupled with the fact that the boys are more likely to suffer from hard tasks at home such as farming, fishing and other domestic upkeep activities.

Our study also demonstrated that moderate-to-heavy intensities of infection with $T$. trichiura or A. lumbricoides are significant predictors of stunting among the children. This is consistent with the findings from previous studies 


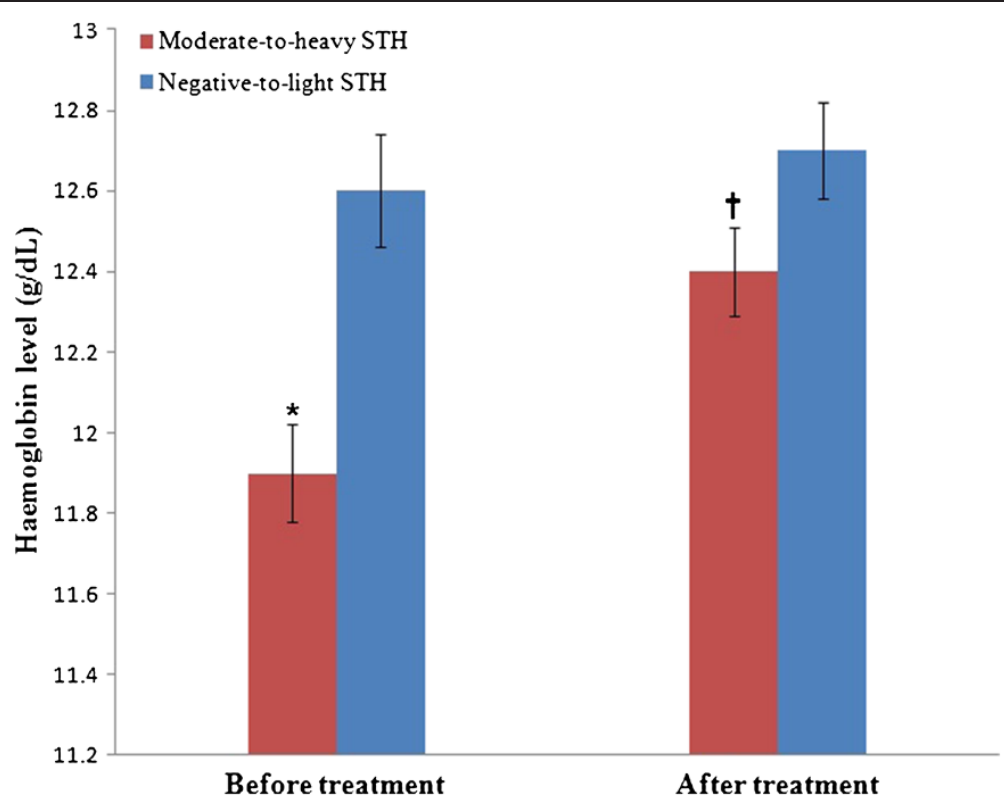

Figure 1 Haemoglobin level in relation to soil-transmitted helmiths infections among the Orang Asli schoolchildren in Satak, Pahang $(\mathbf{n}=\mathbf{2 5 4})$. Values are mean \pm SEM. ${ }^{*}$ Significant difference (lower) compared to negative-to-light STH infection group (Independent t-test, $P<0.05$ ). tSignificant difference (higher) compared to before treatment (repeated measures ANOVA, $P<0.05$ ).

in Peru [38], China [42] and Tanzania [43]. Trichuriasis and ascariasis tend to be very prevalent among children of school age in many endemic areas. More so, STH infections are associated with decreased appetite and low food intake [3], which result to decreased growth rate, poor fitness, decreased activity and poor cognitive function. Micronutrient losses and nutrient malabsorption due to ascariasis and blood-loss due to trichuriasis can lead to iron deficiency, iron deficiency anaemia and poor growth rate $[3,44]$.

Post-treatment assessments following anthelminthic treatment showed that the moderate-to-heavy infected children benefitted more from the deworming and gained more weight than the negative-to-light infected children but the difference was not statistically significant. This agrees with previous studies conducted in India [2], Jamaica [45] and Guatemala [46]. However, Stephenson et al., [3] reported significant improvements in height and weight among the treated Kenyan school boys harbouring multiple helminth infections at 4 months after treatment.

In the present study, the moderate-to-heavy infected children showed a significant increment in the mean haemoglobin concentration after 3 months compared to the negative-to-light infected children. This is in agreement with a clinical trial conducted among Zanzibari preschool children which reported that anthelminthic treatment using mebendazole, significantly reduces anaemia status among the children [47]. The improvement in haemoglobin levels among the subjects following anthelminthic treatment lead to the assumption that the burden of helminthiases is a significant contributor to anaemia in the population.

\section{Conclusions}

Although meaningful achievements have been recorded all over Malaysia in terms of quality of life improvement throughout the years of independence, the Orang Asli (aboriginal) population seems to be left behind by other races in the country such as the Malays, Chinese and Indians, probably due to their remoteness and the desire to stay in the jungles and away from other people. Previous reports findings have shown that the Orang Asli all over the country share similar socioeconomic, health and demographic characteristics. Although their number constitute about $0.6 \%$ of the country's total population, their plight is of great concern. High prevalence of STH infections, anaemia and malnutrition evidently persist among Orang Asli children resulting in negative consequences on their growth, health and overall productivity. In our survey, anthelminthic treatment has produced some positive changes on the nutritional status of the more heavily infected children. It is therefore suggested that beside poverty alleviation and health education, helminth control should be considered as an important intervention programme for the Orang Asli population, both at school and community levels.

Competing interests

The authors' declare that they have no competing interests. 


\section{Acknowledgements}

The authors wish to acknowledge the cooperation and support accorded them by the Headmaster, staff and the entire pupils of Sekolah Kebangsaan Satak, in making this survey a success. We also sincerely appreciate the support and cooperation given to us by the parents, staff of Raub District Education Department, the Medical Director and nursing staff of Cheroh Health Clinic and other community members in the study area, towards the successful conduct of this survey. This study was supported by the University of Malaya research grants (PS181/2009C \& PS233/2010B).

\section{Author details}

'Department of Parasitology, Faculty of Medicine, University of Malaya, Kuala Lumpur 50603, Malaysia. ${ }^{2}$ Department of Parasitology, Faculty of Medicine and Health Sciences, Sana'a University, Sana'a, Yemen.

\section{Authors' contributions}

AA was involved in all phases of the study, including study design, data collection, data analysis and write up of the manuscript; JS, HMA and II supervised the study, and revised the manuscript; HMA was involved in the statistical analysis of data; AHA and AMA were involved in the collection and laboratory examination of samples. All authors read and approved the final manuscript. JS and HMA were the guarantors of the paper.

Received: 3 April 2012 Accepted: 15 June 2012

Published: 15 June 2012

\section{References}

1. Crompton DWT, Nesheim MC: Nutritional impacts of Intestinal helminthiasis during the human life cycle. Ann Rev Nutr 2002, 22:35-59.

2. Nallam NR, Paul I, Gnanamani G: Anemia and hypoalbuminia as an adjunct to soil-transmitted helminthiasis among slum school children in Visakhapatnam, South India. Asia Pac J Clin Nutr 1998, 7(2):164-169.

3. Stephenson LS, Latham MC, Adam EJ, Kinoti SN, Pertet A: Physical fitness, growth and appetite of Kenyan school boys with Hookworm, Trichuris trichiura and Ascaris lumbricoides infections are improved four months after a single dose of albendazole. J Nutr 1993, 123:1036-1046.

4. Park K: Park's Textbook of Preventive and Social Medicine. Jabalpur: Banarsidas Bhanot; 2002.

5. Khor GL: Micronutrient status and intervention programs in Malaysia. Food Nutr Bull 2005, 26(2):S281-S285.

6. WHO: Iron deficiency anaemia: Assessment, prevention and control. Geneva: World Health Organization; 2001.

7. Stoltzfus RJ: Iron deficiency: global prevalence and consequences. Food nutr bull 2003, 24(Suppl):99-103.

8. Haas JD, Brownlie TT: Iron deficiency and reduced work capacity: A critical review of the research to determine a causal relationship. J Nutr 2001, 131:676S-688S

9. Gordon N: Iron deficiency and the intellect. Brain Dev 2003, 25:3-8

10. Allen LH: Anaemia and iron deficiency: Effects on pregnancy outcome. Am J Clin Nutr 2000, 71(Suppl):1280-1284.

11. Menendez C, Fleming AF, Alonso PL: Malaria-related anaemia. Parasitol Today 2000, 16:469-476.

12. Quihui-Cota L, Valencia ME, Crompton DWT, Phillips S, Hagan P, DiazCamacho SP, Tejas AT: Prevalence and intensity of intestinal parasitic infections in relation to nutritional status in Mexican schoolchildren. Trans R Soc Trop Med Hyg 2004, 98:653-659.

13. MOH: Annual Report. Kuala Lumpur, Malaysia: Ministry of Health; 2000.

14. Al-Mekhlafi HM, Surin J, Atiya AS, Ariffin WA, Mahdy AKM, Abdullah HC: Anaemia and iron deficiency anaemia among aboriginal schoolchildren in rural Peninsular Malaysia: an update on a continuing problem. Trans $R$ Soc Trop Med Hyg 2008, 102(10):1046-1052.

15. Nor Aini U, Al-Mekhlafi HM, Azlin M, Shaik A, Sa'iah A, Fatmah MS, Ismail MG, Ahmad Firdaus MS, Aisah MY, Rozlida AR, Moktar N: Serum Iron Status in Orang Asli children living in endemic areas of soil-transmitted helminthes. Asia Pac J Clin Nutr 2007, 16:724-730.

16. Foo $\mathrm{LH}$, Khor $\mathrm{GL}$, Tee $\mathrm{ES}$ : Iron status and dietary intake of adolescents from rural community in Sabah, Malaysia. Asia Pac J Clin Nutr 2004, 13(1):48-55.

17. Sagin DD, Ismail G, Mohamad M, Pang EKH, Sya OT: Anemia in Remote interior communities in Sarawak, Malaysia. Southeast Asian I Trop Med Pub Health 2002, 33(2):373-377.
18. Ahmed A, Al-Mekhlafi HM, Choy SH, Ithoi I, Al-Adhroey AH, Awatif MA, Surin $\mathrm{J}$ : The burden of moderate-to-heavy soil-transmitted helminth infections among rural Malaysian Aborigines: An urgent need for an integrated control programme. Parasit Vectors 2011, 4:242.

19. Al-Mekhlafi HMS, Azlin M, NorAini U, Shaik A, Sa'aih A, Fatmah A, Ismail MG, Ahmad Firdaus MS, Aisah MY, Rozlida AR, Moktar N: Malnutrition and soiltransmitted helminthiasis among Orang Asli children in Selangor, Malaysia. Asia Pac J Clin Nutr 2005, 14:188-194.

20. Al-Mekhlafi HM, Surin J, Atiya MS, Ariffin WAW, Mahdy MAK, Abdullah HC: Pattern and predictors of soil-transmitted helminth re-infection among aboriginal school children in rural peninsular Malaysia. Acta Trop 2008, 107:200-204.

21. WHO: Use and Interpretation of anthropometric indicators of nutritional status. Bull World Health Organ 1986, 64:929-941.

22. WHO: Basic Laboratory Methods in Medical Parasitology. Geneva: World Health Organization; 1991.

23. WHO: Prevention and control of intestinal parasitic infections: Prevention and control of schistosomiasis and soil-transmitted helminthiasis. Technical Report Series No. 912. Geneva: World Health Organisation; 2002.

24. Bendel RB, Afifi AA: Comparison of stopping rules in forward regression. J Am Stat Ass 1977, 72:46-53.

25. Rao TV, Vijai T: Malnutrition and anaemia in tribal pediatric population of Purnia district (Bihar), India. Indian Pediatr 2006, 43:181-182.

26. Knopp S, Mohammed KA, Stothard JR, Khamis IS, Rollinson D, Marti H, Utzinger J: Patterns and risk factors of helminthiasis and anaemia in a rural and peri-urban community in Zanzibar, in the context of helminth control programs. PLoS Negl Trop Dis 2010, 4(5):e681.

27. Luo R, Wang X, Zhang L, Liu C, Shi Y, Miller G, Rozelle S, Martorell R: High anaemia prevalence in Western China. Southeast Asian J Trop Med Pub Health 2011, 42(5):1204-1213.

28. Norhayati M, Noor Hayati Ml, Oothuman P, Azazi O, Fatmah A, Fatmah MS: Malnutrition and its risk factors among children 1-7 years old in rural Malaysian communities. Asia Pac J Clin Nutr 1997, 6:260-264.

29. Tai MS, Goh K, Siti Hawa MT, Rampal S, Mahadeva S: Anthropometric, biochemical and clinical assessment of malnutrition in Malaysian patients with advanced cirrhosis. Nutr J 2010, 9:27.

30. Bhoite $\mathrm{R}$, lyer U: Magnitude of Malnutrition and IDA among rural schoochildren: An Appraisal. Asian J Exp Biol Sc 2011, 2(2):354-361.

31. Osazuwa F, Ayo OM, Imade P: A significant association between intestinal helminth infection and anaemia burden in children in rural communities of Edo state, Nigeria. North Am J Med Sc 2011, 3(1):30-34.

32. Shoeps DO, de Abreu LC, Valenti VE, Nascimento VG, de Oliveira HG, Gallo $P R$, Wajnsztejn R, Leone C: Nutritional status of pre-school children from low income families. Nutr J 2011, 10:43.

33. Calis JC, Phiri KJ, Farragher EB: Severe anaemia in Malawian children. New Eng J Med 2008, 358(9):888-899.

34. Brooker S, Peshu N, Warn PA, Mosobo M, Guyatt HL, Marsh K, Snow RW: The epidemiology of hookworm infection and its contribution to anaemia among pre-school children on the Kenya coast. Trans $R$ Soc Trop Med Hyg 1999, 93:240-246.

35. Stoltzfus RJ, Chwaya HM, Tielsch JM, Schultz KJ, Albonico M, Savioli L: Epidemiology of iron deficiency anaemia in Zanzibari schoolchildren; the importance of hookworms. Am J Clin Nutr 1997, 65:153-159.

36. Stoltzfus RJ, Albonico M, Chwaya HM, Savioli L, Tielsch JEA: Hemoquant determination of hookworm-related bloodloss and its role in iron deficiency in African children. Am J Trop Hyg 1996, 55:399-404.

37. de Silva BR, Brooker S, Hotez PJ, Montressor A, Engels D, Savioli L. Soil-transmitted helminth infections: Updating the global picture. Trends Parasitol 2003, 27:547-551.

38. Gasapia M, Joseph SA, Nunez C, Rahme E, Gyorkos TW: Parasite risk factors for stunting in grade 5 students in a community of extreme poverty in Peru. Int J Parasitol 2006, 36:741-747.

39. Mostafa KS: Socio-economic determinants of severe and moderate stunting among under-five children in rural Bangladesh. Malay J Nutr 2011, 17(1):105-118.

40. Ramli Agho KE, Inder KJ, Bowe SJ, Jacobs J, Dibley MJ: Prevalence and risk factors for stunting and severe stunting among under-fives in North Maluki Province of Indonesia. BMC Pediatr 2009, 9:64.

41. Sapkota VP, Gurung CK: Prevalence and predictors of underweight, stunting and wasting in under-five children. J Nep H Res Council 2009, 7(15):120-126. 
42. Shang YU, Tang LH, Zhou SS, Chen YD, Lin SX: Stunting and soiltransmitted helminth infections among school age pupils in rural areas of southern China. Parasit Vectors 2010, 3:97.

43. Stoltzfus RJ, Albonico M, Tielsch JM, Chwaya HM, Savioli L: Linear growth retardation in Zanzibari schoolchildren. J Nutr 1997, 127:1099-1105.

44. Stephenson LS, Holland CV, Cooper ES: The public health significance of Trichuris trichiura. Parasitol 2000, 121:S73-S95.

45. Simeon DT, Grantham-McGregor SM, Callender JE, Wong MS: Treatment of Trichuris trichiura infections improves growth, spelling scores and school attendance in some children. J Nutr 1995, 125(7):1875-1883.

46. Watkins E, Pollitt E: Effect of removing Ascaris on the growth of Guatemalan schoolchildren. Pediatr 1996, 97(6):871.

47. Stoltzfus RJ, Chwaya HM, Montressor A, Tielsch JM, Jape JK, Albonico M, Savioli L: Low daily dose iron supplementation improves iron status and appetite but not anaemia, whereas quarterly anthelminthic treatment imrpoves growth, appetite and anaemia in Zanzibari preschool children. J Nutr 2004, 134(2):348-356.

doi:10.1186/1756-3305-5-119

Cite this article as: Ahmed et al:: The nutritional impacts of soiltransmitted helminths infections among Orang Asli schoolchildren in rural Malaysia. Parasites \& Vectors 2012 5:119.

\section{Submit your next manuscript to BioMed Central and take full advantage of:}

- Convenient online submission

- Thorough peer review

- No space constraints or color figure charges

- Immediate publication on acceptance

- Inclusion in PubMed, CAS, Scopus and Google Scholar

- Research which is freely available for redistribution 